7. Child Lang. 30 (2003), $47 \mathrm{I}-485$. (C) 2003 Cambridge University Press DOI: I0.1017/So305000903005580 Printed in the United Kingdom

N O T E

\title{
Diminutivization supports gender acquisition in Russian children*
}

\author{
VERA KEMPE \\ University of Stirling \\ PATRICIA J. BROOKS \\ The College of Staten Island and the Graduate School of the City \\ University of New York \\ NATALIJA MIRONOVA And OLGA FEDOROVA \\ Moscow State University \\ (Received 25 April 2002. Revised I November 2002)
}

\begin{abstract}
Gender agreement elicitation was used with Russian children to examine how diminutives common in Russian child-directed speech affect gender learning. Forty-six children $(2 ; 9-4 ; 8)$ were shown pictures of familiar and of novel animals and asked to describe them after hearing their names, which all contained regular morphophonological cues to masculine or feminine gender. Half were presented as simplex (e.g. jozh 'porcupine') and half as diminutive forms (e.g. jozhik 'porcupineDIM'). Children produced fewer agreement errors for diminutive than for simplex nouns, indicating that the regularizing features of diminutives enhance gender categorization. The study demonstrates how features of child-directed speech can facilitate language learning.
\end{abstract}

\section{INTRODUCTION}

Grammatical category learning is a fundamental component of language acquisition because grammatical categories lie at the basis of morphology and

[*] This study was supported by NATO collaborative linkage grant \#975293 awarded to Patricia Brooks, Olga Fedorova, and Vera Kempe. We would like to thank the children, parents, and staff at day care centres \#250, 735, 859, and 2023 of the city of Moscow for their participation and support of the study. Address for correspondence: Vera Kempe, Department of Psychology, University of Stirling, Stirling, FK9 4 LA, Scotland, UK. e-mail:vera.kempe@stir.ac.uk 
syntax. One fundamental category that has received much attention in research on language development is the category of gender (e.g. Popova, I973; Karmiloff-Smith, I979; Levy, I983; Mills, I985; Mulford, I985; Smoczynska, I985; Pérez-Pereira, I991). Gender, when present in a language, is of great importance as it determines inflectional processes of agreement, reference, and declension. Gender categorization in itself, however, tends to be very complex because it can be based on a range of semantic and morphosyntactic features. Although in many languages, semantic dimensions tend to lie at the core of the gender distinction (Corbett, I99I), they are always supplemented by a variety of formal features that render the mapping of nouns to gender categories semi-arbitrary. That is, while sexuated entities like men and women may constitute the core of the masculine and feminine gender categories, in many languages these categories extend to inanimate nouns without any obvious semantic basis for classification. For example, the Spanish noun libro [book] is masculine whereas its Russian translation kniga $a^{1}$ is feminine; Spanish mesa [table] is feminine whereas its Russian translation stol is masculine. Even within nouns denoting humans, semantic dimensions may be obscured as examples like the neuter German noun Mädchen [young girl] suggest.

In the absence of clear semantic correlates of grammatical gender, formal morphophonological features play an important role in gender learning and processing (Bates, Devescovi, Pizzamiglio, D’Amico \& Hernandez, I 995; Taraban \& Kempe, I 999; Vigliocco \& Franck, I 999). Languages vary widely with respect to the transparency of morphophonological gender markers. At one extreme are languages like German, for which Köpcke \& Zubin ( 1984 ) proposed over 50 probabilistic cues to gender, most of which were morphophonological in nature. At the other extreme are languages like Russian with just three predominant marking patterns for masculine, feminine, and neuter nouns. Masculine nouns tend to end in consonants, feminine nouns in - $a$ or its allomorphs, and neuter nouns in -o or its allomorphs. Despite this apparent transparency, Russian, like many Slavic and Romance languages, has exceptions to the predominant patterns, rendering morphophonological marking of gender quasi-regular. Given these complexities, studying the acquisition of gender provides an instructive case to probe children's ability to learn complex grammatical categories.

We will now briefly describe the structure of the Russian gender system in more detail to highlight the challenges that a learner of the language faces. In addition to the three predominant marking patterns described above, Russian has a class of nouns ending in palatalized consonants that can be either masculine (pen' [stump]) or feminine (pech' [oven]) because they do not

[I] In the transcription of Russian we follow the transliteration rules used by Comrie \& Corbett ( I 992). 
contain any morphophonological features providing cues to gender category membership. Based on estimates from the 200 most frequent Russian nouns (Zasorina, I977), these non-transparent nouns comprise about 10\% of noun types. Furthermore, Russian has a class of inconsistently gender-marked masculine nouns that end in $-a$ and take the feminine declension paradigm. However, these nouns refer to male entities like 'man' (muzhchina), and require masculine gender agreement. This pattern is especially common for Russian masculine proper names, the nicknames of which tend to resemble the form of feminine nouns, e.g. Ivan - Vanja or Konstantin - Kostja. ${ }^{2}$

The existence of non-transparent and inconsistent nouns in a predominantly regular gender-marking language like Russian presents a considerable learnability problem for the child. Smoczynska (i985), in particular, has argued that the presence in the child's language input of feminine (e.g. pech') and masculine (e.g. pen') nouns ending in palatalized consonants in the nominative case may considerably obscure the distinction between masculine and feminine. ${ }^{3}$ Furthermore, the presence of inconsistently marked masculine nouns and nicknames like Vanja, which tend to be very frequent in children's language input, adds to the confusion. Finally, the acoustic similarity of the unstressed endings of many feminine $(-a)$ and neuter $(-o)$ nouns, which is common in a number of variants of Russian, may lead to difficulties in acquiring the distinction between feminine and neuter, at least as long as the learner relies exclusively on spoken language input. Thus, despite the considerable transparency of the Russian gender system as compared to a language like German, learners are still left with substantial challenges that render gender acquisition a complex learnability problem.

However, research on the effects of child-directed speech (CDS) suggests that this speech register may have certain features that help to alleviate this problem. Russian, as well as Spanish CDS, is characterized by a pervasive use of diminutives (Andrews, I 995; Kempe, Brooks \& Pirott, 200 I). Diminutives are morphological derivations expressing smallness, endearment, and affection (Jurafsky, I 996) that commonly appear in CDS of many speech communities. In some languages, such as English, diminutive derivations, e.g. doggy, bootie, or Patty, may be restricted to a very limited number of common nouns and proper names. In other languages, such as Russian, almost any concrete noun can be diminutivized leading to forms such as stolik [*tabl-y, 'little table'] or lampochka [*lamp-y, 'little lamp']. Russian

[2] It should be noted that both of these types of irregularities are not unique to Russian, but are found in a number of other languages. For example, in Spanish, while masculine nouns tend to end in $-o$, and feminine nouns in $-a$, the language contains non-transparent nouns (e.g. coche [car-masc], noche [night-fem]) as well as inconsistently gender-marked nouns (e.g. mapa [map-masc], mano [hand-fem]).

[3] Because masculine and feminine non-transparent nouns take different declension paradigms gender ambiguity is only apparent in the nominative case. 
possesses a variety of diminutive suffixes (Voeykova, I 998): masculine diminutive nouns typically end in affixes such as $-i k$, $-e k$, or $-o k$, neuter nouns end in affixes such as $-k o,-s h k o,-c h k o$, or $-c e$ and feminine nouns end in the affix $-k a$. Furthermore, diminutivization can be applied iteratively to the same noun by using diminutive infixes such as -ech or -ich, as in mysh' [mouse], myshka [mouse-DIM], myshechka [mouse-DIM-DIM]. Normal discourse with Russian children involves the ubiquitous use of diminutives (Kempe et al., 2001), especially with words for animals, body parts, and household items (i.e. the most frequently occurring nouns in the child's language environment).

We have proposed (Kempe \& Brooks, 200I, see also Olmsted, I994) that in some languages, including Russian, diminutives may facilitate gender category learning for two reasons. First, they regularize noun endings, thereby providing greater consistency in gender category marking. Non-transparent nouns, e.g. korabl' [ship-masc], morkov' [carrot-fem], when diminutivized show the predominant morphosyntactic gender marking patterns of masculine and feminine nouns, e.g. korablik [ship-DIM-masc], morkovka [carrotDIM-fem]. Second, diminutivization results in greater within-category similarity of noun endings, which also might promote the acquisition of gender. Thus, all masculine diminutive nouns end in $-k$, whereas simplex masculine nouns may end in any consonant; all feminine diminutive nouns end in $-k a$, whereas in simplex feminine nouns any consonant may precede the final $-a$ or its allomorph $-j a$, and all neuter diminutive nouns end in $-k o$ or $-c e$, whereas in simplex neuter nouns different consonants can precede the suffix $-o$ or its allomorphs $-j o$ and $-e$. Because Russian diminutives are so pervasive (Kempe et al., 200I), a large proportion of the input to a child contains forms that could contribute to regularizing and simplifying Russian gender marking.

It has been argued (Smoczynska, I985), however, that diminutives may confuse Russian children due to a tendency to reverse the gender marking of a few masculine animate nouns in an apparently inconsistent manner. For example, the masculine noun medved' [bear-masc] is typically diminutivized as mishka, and the masculine noun zajac [hare-masc] may be diminutivized as zajchik or zayka. Even though such form reversal commonly applies to very few nouns, it could lead to a situation in which the proposed benefits of diminutivization for gender category learning do not hold.

The experiment reported here examined whether diminutives aid Russianspeaking children in identifying the gender of nouns. To evaluate children's gender categorization, we elicited their production of gender agreement forms, such as pronominal agreement, adjective-noun agreement, and past tense subject-verb agreement, when shown a picture of an animal and asked to describe it after hearing its name. This method is quite similar to the one used by Karmiloff-Smith ( 1979, Experiment 8), in a study of French gender 
acquisition, as we introduced both familiar and novel nouns, and provided no cues to noun gender besides the morphophonological marking of the noun endings. However, unlike Karmiloff-Smith ( I 979), we limited the stimuli to animate nouns because morphosyntactic marking of Russian animate nouns seems to be more arbitrary than that of inanimate nouns due to use of gender form reversing diminutives with some animate nouns (Smoczynska, i 985). Use of animate nouns thus provides a more stringent test of the hypothesis that diminutives aid gender categorization.

Previous experimental research on Russian gender acquisition (Popova, I 973) has focused on just one form of gender agreement, i.e. agreement between nouns and past tense verbs, and has shown that errors persist at least through age $3 ; 6$. However, because Russian has a number of other agreement forms, such as adjective and pronominal agreement, which are also indicative of gender category mastery, we cannot be certain at what age children will be successful at a gender elicitation task that allows freedom in the choice of agreement forms. Therefore, we tested children over a wide range of ages to obtain initial descriptive data on the age at which Russian gender is typically acquired.

\section{METHOD}

\section{Participants}

Forty-six children (24 girls, 22 boys, mean age 3 ; I I, range $2 ; 9$ to $4 ; 8$ ) took part in the study. The children were monolingual speakers of Russian who attended a day care centre in Moscow at the time of testing. All children spoke the variety of Russian that is typical for the Moscow region.

\section{Materials}

A total of 24 coloured drawings of familiar and of unfamiliar, imaginary animals ( 12 in each category) were created. Six of the nouns denoting the familiar animals were masculine, and six were feminine. In addition, we created I 2 Russian pseudo-word labels for the unfamiliar animals. Six of these novel names for the unfamiliar nouns ended in a non-palatalized consonant thus resembling the dominant word from of Russian masculine nouns, and six ended in the suffix $-a$, thus resembling the dominant form of Russian feminine nouns. All 24 nouns were transparently marked for gender. No neuter nouns were included as it is impossible to find a matching number of Russian neuter nouns denoting animals.

All nouns were diminutivized except the nouns (kit [whale-masc], which cannot be diminutivized, and babochka [butterfly-fem]) which is a lexicalized diminutive, and has no corresponding simplex form with a similar core meaning. These nouns were always presented in one form. In order to 
counterbalance this deviation, another masculine and another feminine noun also remained in the same form throughout the experiment (petushok [rooster-DIM-masc] and cherepakha [turtle-SIMPLEX-fem]). ${ }^{4}$ All the nouns and their diminutive derivations as presented in the experiment are listed in the appendix.

The nouns and their diminutive derivations (except for the four unchanged nouns mentioned above) were distributed across two lists in such a way that each noun appeared as simplex in one list, and as diminutive in the other. Each list contained an equal number of simplex and diminutive, familiar and unfamiliar nouns. Children were quasirandomly assigned to the two 'list' groups, matched for sex and age.

\section{Procedure}

Children were tested individually by a female native speaker of Russian in a room adjacent to the main activity room of their day care centre. Children were first shown two practice pictures depicting familiar animals not included in the main experiment (zajac [hare] and medved' [bear]). For each picture, they were first given the name of the animal in nominative case, and asked to repeat it, if necessary several times in order to ensure correct repetition. Then they were asked to talk about the animal through an elicitation question Rasskazhi mne pro eto zhivotnoe. [Tell me about this animal.] This elicitation question always contained the neuter noun zhivotnoe [animal], which does not provide a cue to the gender of the noun denoting the animal. If a child did not produce any utterances, the experimenter tried to elicit responses by asking a set of probing questions like Chto eto zhivotnoe est? [What does this animal eat?] Kakogo cveta eto zhivotnoe? [What colour is this animal ?] Nravitsja li tebe eto zhivotnoe? Pochemu? [Do you like this animal? Why?] In doing so, the experimenter carefully avoided use of gender agreement with personal pronouns, relative pronouns, verbs, and modifiers to provide no clues to noun gender besides the animal name, as given in nominative case at the start of the trial.

Given the large number of stimuli, i.e. 24 per child, elicitation questions were presented until the child provided a single agreement form, or else lost

[4] Despite the fact that diminutivization is highly productive in Russian, some nouns are rarely or never diminutivized, and some nouns do not have simplex counterparts. The presence of words that do not undergo specific derivational processes, such as diminutivization, is characteristic of many morphological systems. Comparable English examples would be nouns that do not take overt plural marking such as fish and sheep. Given the constraints set by the experiment, it was difficult to construct a set of stimulus materials lacking any such fixed noun forms. To ensure that the inclusion of the four nouns that did not vary in form across lists did not influence our results in any way, we conducted an additional set of analyses with these items excluded. The results obtained were virtually identical to those reported below for the full stimulus set. 
interest in talking about the animal. Sessions were audiotaped and lasted about I 5 minutes.

\section{RESULTS}

For each picture, the first instance of gender agreement was transcribed, and the occurrence of correct or erroneous gender agreement was coded. We analysed the first instance of gender agreement for each picture because most children produced only a single instance of gender agreement after several eliciting questions. Children almost exclusively produced masculine and feminine agreement; neuter agreement was produced only in a single case. Thus, agreement errors after hearing a feminine noun implies that the child produced masculine gender agreement, and vice versa.

Of the I IO4 trials (46 participants, 24 items), 73 (7\%) trials were coded as erroneous gender agreement, and $997(90 \%)$ trials as correct gender agreement. The remaining $34(3 \%)$ trials were coded as 'lost', mainly because children failed to provide any form of gender agreement, and very occasionally because the experimenter inadvertently revealed the gender of the noun or omitted a picture. Error rates varied considerably across children, ranging from $\circ \%$ to $30 \%$ agreement errors (S.D. $=8 \%$ ). Sixteen children (mean age $4 ; 0$, range $3 ; \mathrm{I}-4 ; 8$ ) were at ceiling on the task and produced no agreement errors. The remaining 30 children (mean age $3 ;$ io, range $2 ; 9-4 ; 5$ ) produced an average of I I \% agreement errors (range $4-30 \%$; S.D. $=8 \%)$. Agreement error rates were weakly correlated with child age in months, $r(N=46)=-0.25, p<0 \cdot 05$, one-tailed.

Table I shows the frequency and percentages of agreement errors as a function of noun familiarity, derivational status of the noun, and noun gender for the full and the reduced sample. We performed a (2) noun familiarity: familiar vs. novel $\times(2)$ derivational status: simplex vs. diminutive $\times(2)$ gender: feminine vs. masculine within-subjects ANOVA on agreement errors, computed as proportions of completed trials, correcting for the number of lost trials per subject and condition. This analysis revealed a main effect of derivational status, $F(\mathrm{I}, 45)=6 \cdot 6, p<0.05, \eta^{2}=0.0 \mathrm{I}$ I, with fewer errors for diminutive nouns than for their simplex counterparts. There were also significant main effects of noun familiarity, $F(\mathrm{r}, 45)=\mathrm{I} 3 \cdot 6, p=$ $0.00 \mathrm{I}, \eta^{2}=0.04 \mathrm{I}$, indicating that agreement errors were more frequent for novel than for familiar nouns, and gender, $F(\mathrm{I}, 45)=\mathrm{I} 5 \cdot 3, p<0.00 \mathrm{I}, \eta^{2}=$ 0.077 , indicating that agreement errors were more frequent for feminine than for masculine nouns. A significant interaction between noun familiarity and gender, $F(\mathrm{I}, 45)=7 \cdot 4, p<0.0 \mathrm{I}, \eta^{2}=0.0 \mathrm{I} 9$, suggests that the familiarity effect was mainly carried by the feminine nouns, as the error rates for masculine nouns exhibited a floor effect. None of the other interactions were significant.

As one-third of our sample performed at ceiling on the gender elicitation task, we conducted an additional (2) noun familiarity: familiar vs. novel $\times(2)$ 
TABLE I. Frequencies and mean percentages (in parentheses) of occurrence of different agreement errors as a function of noun familiarity, derivational status, and gender for the full sample $(\mathrm{N}=46)$, and for the reduced sample $(\mathrm{N}=30)$

\begin{tabular}{cccccc}
\hline & \multicolumn{2}{c}{ Simplex nouns } & & \multicolumn{2}{c}{ Diminutive nouns } \\
\cline { 2 - 3 } \cline { 6 - 6 } & Feminine & Masculine & & Feminine & Masculine \\
\hline Familiar nouns & 8 & $\mathrm{I}$ & & 6 & 3 \\
Full & $(7 \cdot 6 \%)$ & $(0 \cdot 7 \%)$ & & $(4 \cdot 7 \%)$ & $(2 \cdot 2 \%)$ \\
Reduced & $(\mathrm{I} \cdot 7 \%)$ & $(\mathrm{I} \cdot \mathrm{I} \%)$ & & $(7 \cdot 2 \%)$ & $(3 \cdot 3 \%)$ \\
Novel nouns & 29 & 5 & & $\mathrm{I} 8$ & 3 \\
Full & $(22 \cdot 8 \%)$ & $(5 \cdot 0 \%)$ & & $(\mathrm{I} 3 \cdot 0 \%)$ & $(2 \cdot 2 \%)$ \\
Reduced & $(34 \cdot 9 \%)$ & $(7 \cdot 7 \%)$ & & $(20 \cdot 0 \%)$ & $(3 \cdot 3 \%)$ \\
\hline
\end{tabular}

derivational status: simplex vs. diminutive $\times(2)$ gender: feminine vs. masculine within-subjects ANOVA on error proportions for the reduced sample, excluding the 16 children who produced no errors. The results of this analysis were identical to the previous one (significant main effects of derivational status, $F(\mathrm{I}, 29)=7 \cdot \mathrm{I}, p<0.02, \eta^{2}=0.016$, noun familiarity, $F(\mathrm{I}, 29)=\mathrm{I} 6 \cdot 0$, $p<0.00 \mathrm{I}, \eta^{2}=0.063$, and gender, $F(\mathrm{I}, 29)=\mathrm{I} 8.4, p<0.00 \mathrm{I}, \eta^{2}=0 . \mathrm{I} \mathrm{I} 8$, and $\mathrm{a}$ significant two-way interaction of noun familiarity and gender, $F($ I , 29) $=8 \cdot 0$, $p<0.0 \mathrm{I}, \eta^{2}=0.030$.

Children spontaneously produced six different forms of gender agreement. The most common form was pronominal agreement involving personal pronouns, followed, in decreasing rank, by adjective agreement, agreement with relative and demonstrative pronouns, past tense verb agreement, and finally, oblique case-marking of the noun which is indicative of the noun's gender. Table 2 shows the distribution of the different agreement forms for correct and erroneous gender agreement across all nouns. ${ }^{5}$ To examine whether gender agreement error rates varied as a function of agreement type, we conducted a (2) response type: correct vs. erroneous $\times(2)$ agreement type: adjective vs. personal pronoun ANOVA on the responses for the two most prevalent agreement types (accounting for $95 \%$ of responses). The dependent variable was the proportion of responses for each of the four above defined categories out of the total number of responses. These proportions do not sum up to $\mathrm{I} \cdot \mathrm{O}$ because of instances of relative and demonstrative pronominal agreement, past tense verb agreement, participles, and oblique case marking (accounting for $5 \%$ of responses). This analysis revealed a main effect of response type, $F(\mathrm{I}, 45)=9 \mathrm{I} 4 \cdot 8, p<0 \cdot 00 \mathrm{I}$, confirming that correct responses were more frequent than erroneous ones, a main effect of agreement type,

[5] The distribution of agreement types was virtually identical for familiar and novel nouns indicating that noun familiarity had no effect on agreement type choice. 
TA B LE 2. Frequency and percentage of occurrence of different agreement types for correct and erroneous gender agreement responses $(\mathrm{N}=46)$

\begin{tabular}{|c|c|c|c|}
\hline Agreement type & $\begin{array}{l}\text { Correct } \\
\text { gender } \\
\text { agreement }\end{array}$ & $\begin{array}{l}\text { Erroneous } \\
\text { gender } \\
\text { agreement }\end{array}$ & Total \\
\hline $\begin{array}{l}\text { Personal pronoun } \\
\text { (e.g. on }[\text { he], ona }[\text { she]) }\end{array}$ & $\begin{array}{l}726 \\
(67 \cdot 8 \%)\end{array}$ & $\begin{array}{l}43 \\
(4 \cdot 0 \%)\end{array}$ & $\begin{array}{l}769 \\
(7 \mathrm{I} \cdot 9 \%)\end{array}$ \\
\hline $\begin{array}{l}\text { Adjective } \\
\text { (e.g. khoroshyj [good-masc], } \\
\text { khoroshaja [good-fem]) }\end{array}$ & $\begin{array}{l}23 \mathrm{I} \\
(2 \mathrm{I} \cdot 6 \%)\end{array}$ & $\begin{array}{l}27 \\
(2 \cdot 5 \%)\end{array}$ & $\begin{array}{l}258 \\
(24 \cdot 1 \%)\end{array}$ \\
\hline $\begin{array}{l}\text { Relative and demonstrative pronoun } \\
\text { (e.g. etot }[\text { this-masc], eta }[\text { this-fem]; } \\
\text { kotoryj }[\text { who-masc], kotoraja }[\text { who-fem] })\end{array}$ & $\begin{array}{l}25 \\
(2 \cdot 3 \%)\end{array}$ & $\begin{array}{l}3 \\
(0 \cdot 3 \%)\end{array}$ & $\begin{array}{l}28 \\
(2 \cdot 6 \%)\end{array}$ \\
\hline $\begin{array}{l}\text { Past tense verb } \\
\text { (e.g. } b y l[\text { was-masc], } b y l a \text { [was-fem]) }\end{array}$ & $\begin{array}{l}\text { II } \\
(\mathrm{I} \cdot 0 \%)\end{array}$ & $\begin{array}{l}\circ \\
(0 \%)\end{array}$ & $\begin{array}{l}\text { I I } \\
(\mathrm{I} \cdot O \%)\end{array}$ \\
\hline $\begin{array}{l}\text { Participle } \\
\text { (e.g. pokhozh [similar-masc], } \\
\text { pokhozha }[\text { similar-fem]) }\end{array}$ & $\stackrel{3}{(0 \cdot 3 \%)}$ & $\begin{array}{l}\circ \\
(\circ \%)\end{array}$ & $\begin{array}{l}3 \\
(0 \cdot 3 \%)\end{array}$ \\
\hline $\begin{array}{l}\text { Oblique case marking } \\
\text { (e.g. jozhikom [porcupine-masc-instr]) }\end{array}$ & $\begin{array}{l}\text { I } \\
(0 \cdot I \%)\end{array}$ & $\begin{array}{l}\circ \\
(\circ \%)\end{array}$ & $\begin{array}{l}\text { I } \\
\left(0 \cdot I_{0} \%\right)\end{array}$ \\
\hline
\end{tabular}

$F(\mathrm{I}, 45)=26 \cdot \mathrm{I}, p<0.00 \mathrm{I}$, indicating that agreement with personal pronouns was more frequent than adjective agreement. Most importantly, we found a significant interaction, $F(\mathrm{I}, 45)=30 \cdot 8, p<0.00 \mathrm{I}$, suggesting that adjectival agreement is proportionally more error-prone than pronominal agreement. Thus, errors were more prevalent for agreement between nouns and adjectives (e.g. khoroshij lisa [good-masc fox-fem]) than between nouns and personal pronouns (e.g. lisa ... on [fox-fem ... he]). Note that correct agreement with adjectives requires selection of the correct suffix while correct agreement involving personal pronouns requires just the selection of the correct pronoun. It is of interest that the 16 children who performed at ceiling on our task used agreement with personal pronouns in $83 \%$ of their responses in comparison to the remaining 30 children who used personal pronouns in only $64 \%$ of their responses. Hence, the differences in performance observed across children might be partially attributable to their choice of agreement type.

\section{DISCUSSION}

Our main goal was to examine whether diminutivization facilitates or hinders gender acquisition in Russian children. We found a beneficial effect of diminutivization with children committing fewer gender agreement errors when presented with a diminutive noun as opposed to its simplex counterpart. This benefit was observed in animate nouns, which comprise the 
most ambiguously marked portion of the Russian noun system due to the possibility of gender form reversing diminutivization (e.g. medved'-mishka). Thus, despite the fact that in Russian, diminutive usage occasionally obscures the gender marking of some simplex animate nouns, the beneficial effects of diminutives appear to outweigh the disadvantages. As outlined above, we suspect that two mechanisms underlie the advantageous effects of diminutives on Russian gender learning. First, diminutives affect the distribution of unambiguous gender marking in Russian through regularization of the endings of nominative non-transparently gender-marked nouns. Increased frequency of regular gender marking reduces the difficulty of gender categorization for the learner. Second, diminutives increase the within-gender category similarity and perceptual salience of regular endings, thus facilitating the recognition of morphophonologial gender marking. In other words, Russian diminutive affixes happen to be especially strong and salient cues to noun gender.

This finding complements our recent work on Russian gender learning in English-speaking adults (Kempe \& Brooks, 200I). Using a miniature language learning paradigm, adults lacking any prior knowledge of the Russian language were exposed to 30 Russian nouns over a period of four I -hour training sessions. During the sessions, the adults heard noun phrases consisting of a noun plus a gender-marked colour adjective (e.g. krasnaja skripka [red-fem violin], krasnyj dom [red-masc house]) while viewing coloured line drawings of corresponding objects. Participants were instructed to try to learn the Russian words for the colours of the pictures. The derivational status of the nouns was manipulated in a between-subjects design with half of the learners exposed to diminutive derivations, and the other half to the corresponding simplex forms of the 30 nouns. After the fourth training session, both groups were given a generalization test consisting of a mixture of familiar and novel diminutive and simplex nouns, along with corresponding pictures. Participants were asked to produce the correct colour adjective for each noun presented. We found that the diminutive training group learned the gender categories faster, and made fewer errors in adjective-noun gender agreement in the generalization test, than the group exposed to simplex nouns. Note, however, that there was no direct transfer of gender from diminutive training items to the respective nontransparent simplex forms of nouns presented during testing. This suggests that diminutives facilitate gender learning by aiding the learner in recognizing morphophonological gender cues rather than by fostering an associative link between abstract gender and a lexical representation of a noun. In sum, experimental research on second-language learners clearly demonstrates beneficial effects of diminutivization in Russian gender learning. The current results with Russian children strengthen this finding by showing facilitation from diminutivization in individuals exposed to the Russian noun system in all 
its complexity in their everyday lives. In future work, it will be important to examine whether this benefit extends to learning other aspects of the complex Russian inflectional system such as noun declension.

In addition to the facilitative effect of diminutives, the data revealed several other interesting findings. First, gender agreement errors were more common for novel nouns than for familiar nouns, and were much more common for feminine nouns being than for masculine nouns. The effects of noun familiarity and gender interacted, with performance for feminine novel nouns being far worse than for feminine familiar nouns. The same familiarity effect was not apparent in masculine nouns due to near-ceiling performance. The fact that children showed better performance for familiar nouns suggests that item-based learning, by which agreement patterns are associated with individual nouns, may lie at the core of the learning process. The fact that children readily generalized their knowledge about regular gender marking to novel nouns suggests that they are moving towards the extraction of more general gender cues based on the noun endings.

Our observation of better performance for masculine nouns than for feminine nouns appears to contrast with Popova (1973), who reported that initially many Russian children produce only feminine past tense verb agreement forms. In her study, children of ages $1 ; 10-3 ; 6$ were given familiar object and animal names and were prompted to produce sentences describing the actions of these objects. Popova observed that 22 out of 55 children produced more past tense verb agreement errors for masculine than for feminine nouns, 9 produced more errors for feminine than for masculine nouns, and 24 were balanced in their errors as a function of noun gender. We might speculate that the feminine verb suffix -la may at first be regarded as an overt past-tense marker rather than a gender agreement marker, and thus may be overgeneralized to masculine nouns. This is because Russian past tense verbs agreeing with feminine and neuter nouns end in vowels (-la feminine; -lo neuter) while past tense verbs agreeing with masculine nouns end in the consonant $-l$. This consonantal ending makes masculine verb endings more similar to present tense verbs, which also end in consonants in the third person. We suspect that these pluri-functional salient vowel endings on feminine and neuter past tense verbs might initially be associated with past tense rather than gender marking. This would have no effect in our study as children produced verb agreement in only a few isolated instances. It is of interest that Popova's oldest participants ( 12 children of ages $3 ; \mathrm{I}-3 ; 6$ ) produced about twice as many past tense verb agreement errors for feminine than for masculine nouns, suggesting a reversal of the gender bias. Given the ages of our participants (mean age $=3 ; \mathrm{II}$ ), her results are actually rather consistent with our finding of superior performance for masculine nouns. The observed masculine bias is in line with the idea that masculine is the unmarked gender in Russian (Akhutina, Kurgansky, Polinsky \& Bates, 
I999), such that falling back onto the unmarked default in situations of uncertainty would lead to more gender agreement errors for feminine nouns. ${ }^{6}$

In our gender elicitation task, we chose an open format to tap into children's knowledge about gender categories as revealed by any form of agreement that children might use. Restricting children's responses to just one agreement type as in the Popova (1973) study introduces a confound as it is not clear whether errors should be attributed to a lack of mastery of gender categories or to a lack of mastery of the particular agreement type tested. Allowing children to use whatever type of agreement they choose eliminates this confound, and provides descriptive data about the distribution of gender agreement errors across agreement types. We observed that errors were distributed differently across the different agreement types (see Table 2), and specifically, that agreement with adjectival modifiers was more error-prone than agreement with personal pronouns. Although it was not our main goal to examine differential mastery of agreement types in Russian children, this finding suggests that agreement with personal pronouns may be acquired first. According to the agreement hierarchy proposed by Corbett ( 1983 ), agreement with personal pronouns is cross-linguistically the most basic type of gender agreement. Our observation is in line with this proposal.

Our main finding that diminutives are beneficial for first language learning, is most likely not a feature unique to the Russian language. There are a number of suggestions of how diminutives, when frequent in the CDS registers of other languages, might facilitate the language learning process, especially for linguistic structures that are otherwise difficult for children to grasp. With respect to the acquisition of morphology and syntax, diminutives may reduce the number of different case-marking paradigms as in Lithuanian (Savickiene, I 998) or different stem allomorphs as in Finnish (Laalo, I 998), thereby facilitating the acquisition of noun declension. With respect to word segmentation, diminutivization might regularize patterns of metric stress thereby simplifying the problem of word segmentation (Jusczyk, I 997).

These ideas notwithstanding, it should be stressed that we are not suggesting that diminutives are always beneficial for the acquisition of morphology and syntax. Consider German, for example, where diminutivization (i.e. adding the suffixes -chen or -lein) changes the gender of masculine and feminine nouns to neuter thus obscuring the basic gender categories. In this language, diminutivization might actually hinder gender acquisition. Consequently, as shown elsewhere (Kempe et al., 200I),

[6] We performed a signal detection analysis to confirm the existence of a masculine default. Although this analysis is problematic given the overall low error rates, it clearly revealed that most children who made gender agreement errors showed a bias for masculine agreement. 
diminutives are very infrequent in German CDS. It seems, then, that CDS registers tend to emphasize the use of diminutives more in cases where diminutives, as a by-product, have beneficial effects for other aspects of language acquisition.

In addition to diminutives, there are other features of CDS that might facilitate the language learning process, and which may work in tandem with diminutives as discussed here. For instance, Kuhl, Andruski, Chistovich, Chistovich, Kozhevnikova, Ryskina, Stolyarova, Sundberg \& Lacerda ( I 997) reported that vowels produced in the CDS registers of English, Russian, and Swedish caretakers were acoustically more distinct than in adultdirected speech. In these languages, CDS presents children with more clearly articulated vowels, which may facilitate their discovery of phonemically contrasting categories of sounds. Woodward \& Aslin ( I 990) noted that post-utterance pauses could serve as a useful cue for detecting word boundaries in fluent speech, and demonstrated that mothers tend to place new words at the end of their child-directed utterances. Golinkoff \& Alioto (I995) went further to show that placing new words at the ends of utterances enhanced word learning in English-speaking adults learning Chinese, and that this benefit occurred only when utterances were spoken in CDS.

Taken together, this growing body of research highlights the need for child language researchers to consider more carefully the nature of the input in their models of language learning. Child-directed speech appears to emphasize semantically and pragmatically motivated forms if they result in an alleviation of whatever learnability problem exists in a given language. It, thus, is an exquisitely tailored source of distributional information from which language structure may be extracted.

\section{REFERENCES}

Akhutina, T., Kurgansky, A., Polinsky, M. \& Bates, E. (r999). Processing of grammatical gender in a three-gender system: experimental evidence from Russian. Fournal of Psycholinguistic Research 28, 695-7 13.

Andrews, E. (I995). Adult speaker and child addressee: usage and perception of Russian diminutives. Russian Language Fournal/Russkii Yazyk 49, 53-64.

Bates, E., Devescovi, A., Pizzamiglio, L., D’Amico, S. \& Hernandez, A. (i 995). Gender and lexical access in Italian. Perception and Psychophysics 57, 847-62.

Comrie, B. \& Corbett, G. G. (Eds.) (1 992). The Slavonic Languages. London: Routledge.

Corbett, G. G. (1983). Hierarchies, targets, and controllers: agreement patterns in Slavic. University Park, PA: The Pennsylvania State University Press.

Corbett, G. G. (r99i). Gender. Cambridge: CUP.

Golinkoff, R. M. \& Alioto, A. (I995). Infant-directed speech facilitates lexical learning in adults hearing Chinese : implications for language acquisition. Fournal of Child Language 22, $703-26$.

Jurafsky, D. (1996). Universal tendencies in the semantics of the diminutive. Language 72, $533-78$.

Jusczyk, P. W. (I 997). The discovery of spoken language. Cambridge, MA: MIT Press. 
Karmiloff-Smith, A. (1979). A functional approach to child language : a study of determiners and reference. Cambridge: CUP.

Kempe, V. \& Brooks, P. J. (200I). The role of diminutives in Russian gender learning: can child-directed speech facilitate the acquisition of inflectional morphology? Language Learning 5I, $22 \mathrm{I}-56$.

Kempe, V., Brooks, P. J. \& Pirott, L. (200r). How can child-directed speech facilitate the acquisition of morphology? In M. Almgren, A. Barrena, M.-J. Ezeizabarrena, I. Idiazabal $\&$ B. MacWhinney (eds), Research on Child Language Acquisition: Proceedings of the 8th Conference of the International Association for the Study of Child Language. Medford, MA: Cascadilla Press.

Köpcke, K.-M. \& Zubin, D. A. (1984). Sechs Prinzipien für die Genuszuweisung im Deutschen: Ein Beitrag zur natürlichen Klassifikation. Linguistische Berichte 93, 26-50.

Kuhl, P. K., Andruski, J. E., Chistovich, I. A., Chistovich, L. A., Kozhevnikova, E. V., Ryskina, V. L., Stolyarova, E. I., Sundberg, U. \& Lacerda, F. (I997). Cross-language analysis of phonetic units in language addressed to infants. Science 277, 684-6.

Laalo, K. (1998). Diminutives in Finnish child-directed and child speech. In S. Gillis (ed.), Studies in the acquisition of number and diminutive marking. Antwerp Papers in Linguistics, 95. Antwerp: Universiteit Anwerpen.

Levy, Y. (1983). It's frogs all the way down. Cognition $\mathbf{1 5}, 75-93$.

Mills, A. E. (1985). The acquisition of German. In D. I. Slobin (ed.), The crosslinguistic study of language acquisition, volume $I$ : The data. Hillsdale, $\mathrm{NJ}$ : Erlbaum.

Mulford, R. (1985). Comprehension of Icelandic pronoun gender: semantic versus formal factors. Fournal of Child Language 12, 443-53.

Olmsted, H. (I994). Diminutive morphology of Russian children: a simplified subset of nominal declension in language acquisition. In Alexander Lipson : In Memoriam. Columbus, $\mathrm{OH}$ : Slavica Inc.

Pérez-Pereira, M. ( I 99I). The acquisition of gender: what Spanish children tell us. Fournal of Child Language 18, $57 \mathrm{I}-90$.

Popova, M. I. (I973). Grammatical elements of language in the speech of preschool children. In C. A. Ferguson \& D. I. Slobin (eds), Studies of child language development. New York: Holt, Rinehart \& Winston.

Savickiene, I. (1998). The acquisition of diminutives in Lithuanian. In S. Gillis (ed.), Studies in the acquisition of number and diminutive marking. Antwerp Papers in Linguistics 95, Antwerp: Universiteit Anwerpen.

Smoczynska, M. (1985). The acquisition of Polish. In D. I. Slobin (ed.), The crosslinguistic study of language acquisition, volume $\mathrm{I}$ : the data. Hillsdale, $\mathrm{NJ}$ : Erlbaum.

Taraban, R. \& Kempe, V. (I 999). Gender processing in native and non-native Russian speakers. Applied Psycholinguistics 2o, i I 9-48.

Vigliocco, G. \& Franck, J. (I 999). When sex and syntax go hand in hand: gender agreement in language production. Fournal of Memory and Language 40, 455-78.

Voeykova, M. D. (1998). Acquisition of diminutives by a Russian child: preliminary observations in connection with the early adjectives. In S. Gillis (ed.), Studies in the acquisition of number and diminutive marking. Antwerp Papers in Linguistics 95. Antwerp: Universiteit Anwerpen.

Woodward, J. Z. \& Aslin, R. N. (I990). Segmentation cues in maternal speech to infants. Poster presented at the International Conference on Infancy Studies, Montreal, Canada.

Zasorina, L. N. E. (1977). Castotnyj slovar' russkogo jazyka. Moscow: Russkij Yazyk. 
FAMILIAR AND NOVEL ANIMAL NAMES IN THEIR SIMPLEX AND DIMINUTIVE FORMS

\begin{tabular}{|c|c|c|}
\hline & Masculine & Feminine \\
\hline \multicolumn{3}{|c|}{ Familiar nouns } \\
\hline & jozh/jozhik [porcupine] & belka/belochka [squirrel] \\
\hline & zhiraf/zhirafik [giraffe] & lisa/lisichka $[\mathrm{fox}]$ \\
\hline & zhuk/zhuchok [beetle] & obes"'jana/obes'janka [monkey] \\
\hline & slon/slonik [elephant] & ptica/ptichka [bird] \\
\hline & petushok [rooster] & cherepakha [turtle] \\
\hline & kit $[$ whale] & babochka [butterfly] \\
\hline \multicolumn{3}{|l|}{ Novel nouns } \\
\hline & zurUn/zurUnchik & $m Y r v a / m$ Yrvochka \\
\hline & zhabUl/zhabUl'chik & vIgla/vIglochka \\
\hline & pusOt/pusOtik & sUra/sUrochka \\
\hline & cOkor/cOkorjok & krjOfa/krjOfochka \\
\hline & farzjAk/farzjAchik & tImza/tImzochka \\
\hline & narAp/narApchik & gljUsha/gljUshechka \\
\hline
\end{tabular}

